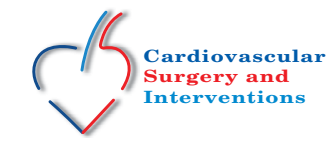

\title{
Coronary subclavian steal syndrome: A case report
}

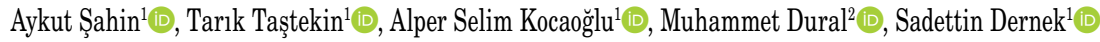 \\ ${ }^{1}$ Department of Cardiovascular Surgery, Eskişehir 0smangazi University Faculty of Medicine, Eskişehir, Turkey \\ ${ }^{2}$ Department of Cardiology, Eskişehir Osmangazi University Faculty of Medicine, Eskişehir, Turkey
}

Received: October 23, 2020 Accepted: November 08, 2020 Published online: March 29, 2021

\begin{abstract}
Coronary subclavian steal syndrome is characterized by reverse flow of the left internal mammary artery used in the coronary artery bypass grafting (CABG). The stenosis in the proximal segment of the left subclavian artery is the reason which consequently leads to disruption of myocardial perfusion. It may cause myocardial infarction with variety of anginal symptoms in patients. In this article, we present a case who had symptoms of dyspnea and angina pectoris after CABG and was diagnosed with subclavian steal syndrome. In conclusion, physical examination and angiographic evaluation for subclavian artery stenosis in the preoperative period is recommended in patients who are scheduled for CABG.
\end{abstract}

Keywords: Coronary artery bypass grafting, coronary subclavian steal syndrome, internal mammary artery.

Subclavian steal syndrome (SSS) is a welldescribed phenomenon characterized by reversal of blood flow in the vertebral artery due to severe stenosis or blockage in the proximal segment of subclavian artery. ${ }^{[1]}$ A special variant of SSS, namely coronary subclavian steal syndrome (CSSS), occurs in cases in whom internal mammary artery (IMA) is used for coronary artery bypass grafting (CABG) in the presence of a narrowed or occluded proximal subclavian artery. This phenomenon leads to a decrease in the IMA blood flow and thus coronary perfusion, possibly leading to myocardial ischemia and angina pectoris. ${ }^{[2]}$ Although most cases are asymptomatic, CSSS has been shown to cause chest pain and effort dyspnea in the postoperative period. ${ }^{[3]}$ In this article, we present a case who had symptoms of dyspnea and angina pectoris after CABG and was diagnosed with SSS.

\section{CASE REPORT}

A 77-year-old woman was admitted with a history of CABG 10 years ago in which the left IMA (LIMA) was anastomosed to the left anterior descending (LAD) coronary artery. Other bypasses were saphenous vein graft to the first obtuse marginal and saphenous vein graft to the second obtuse marginal. She had complaints of exertional dyspnea, chest pain, and exhaustion within the last four months. On physical examination, the heart rate was 80 to $95 \mathrm{bpm}$ and systemic arterial blood pressure ranged between $110 / 70 \mathrm{mmHg}$ and $130 / 80 \mathrm{mmHg}$. Compared to the right upper extremity, there was a systolic pressure gradient of $25 \mathrm{mmHg}$ on the left arm. In addition, the left radial and brachial pulses were weaker. Electrocardiogram showed sinus rhythm without findings indicating myocardial ischemia. Coronary angiography showed that all saphenous grafts were patent. The LIMA filling was not observed in the selective subclavian artery injection (Video 1). However, there was no stenosis in the LIMA during retrograde filling. A $90 \%$ stenosis in the proximal region of the subclavian artery was detected. In her dynamic angiography examination, a critical stenosis at the proximal segment of left subclavian artery in a length of $40 \mathrm{~mm}$ was detected (Video 2). A 7- and 6 -Fr sheaths were placed in the right and left femoral arteries, respectively, using the percutaneous Seldinger technique under local anesthesia. Subsequently, a pigtail catheter was placed at the level of the aortic

Corresponding author: Aykut Şahin, MD. Eskişehir Osmangazi Üniversitesi Tıp Fakültesi, Kalp ve Damar Cerrahisi Anabilim Dalı, 26040 Meşelik, Eskişehir, Türkiye.

Tel: +90 505 - 8310588 e-mail: draykutsahin@gmail.com

\section{Citation:}

Şahin A, Taştekin T, Kocaoğlu AS, Dural M, Dernek S. Coronary subclavian steal syndrome: A case report. Cardiovasc Surg Int 2021;8(1):63-67. 
arch and a vertebral catheter was inserted to subclavian artery. Access to the brachial artery level was achieved by crossing the stenotic vascular segment using a hydrophilic guide wire (035”). Contrast infusion through the pigtail catheter revealed a stenotic segment of dissection, which was marked. A peripheral vascular self-expandable stent $(8 \mathrm{~mm} \times 40 \mathrm{~mm} \times 120 \mathrm{~cm})$ was appropriately placed in the relevant segment (NAVALIS ${ }^{\circledR}$, Tsunamed Inc., Hamburg, Germany). The stent and ostium of the left subclavian artery in the aortic arch were expanded under 6 atmosphere pressure using an $8 \mathrm{~mm} \times 60 \mathrm{~mm} \times 135 \mathrm{~cm}$ drugcoated percutaneous transluminal angioplasty (PTA) balloon (RD Global Inc., Ankara, Turkey) (Video 3).

Control angiography revealed that the dissected stenotic segment was corrected, and complete patency was achieved (Video 4). The reverse flow in the LIMA graft corrected to the proper direction and the flow was sufficient (Figure 1). No any complication occurred after the intervention. As for medical therapy, acetyl salicylic acid $100 \mathrm{mg}$ and clopidogrel $75 \mathrm{mg}$ was continued. In the post-procedure early follow-up of the patient, the chest pain and the effort-related angina pectoris has relieved. The firstmonth computed tomography angiography (CTA) revealed full patency of the left subclavian artery

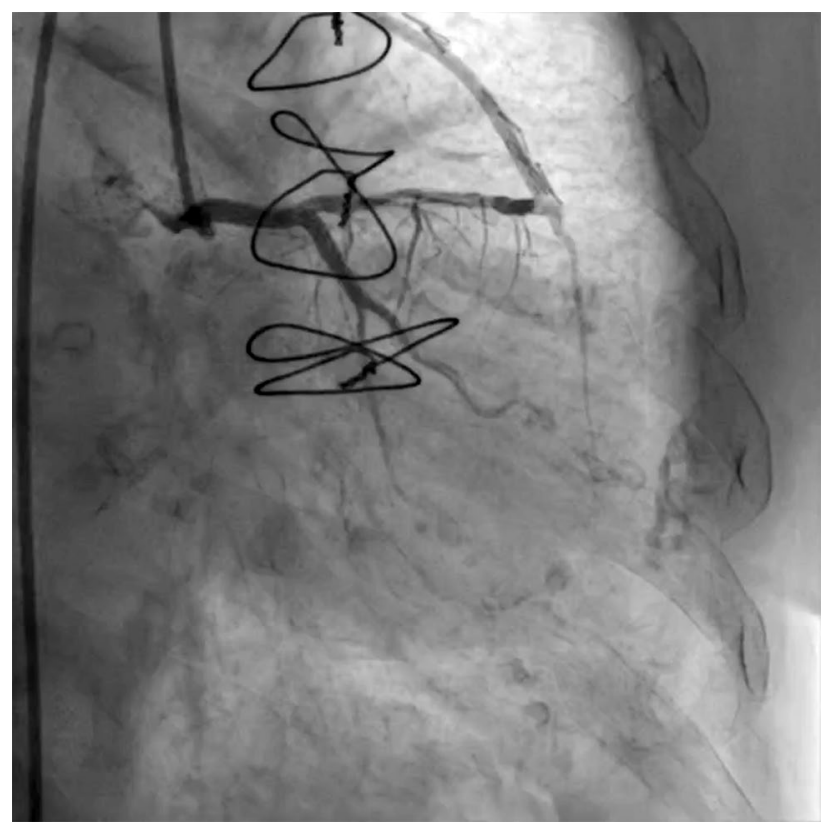

Video 1. Coronary steal syndrome from LAD-to-LIMA-tosubclavian artery.

LAD: Left anterior descending; LIMA: Left internal mammary artery. and the LIMA. After one year, the patient has been still asymptomatic. A written informed consent was obtained from the patient.

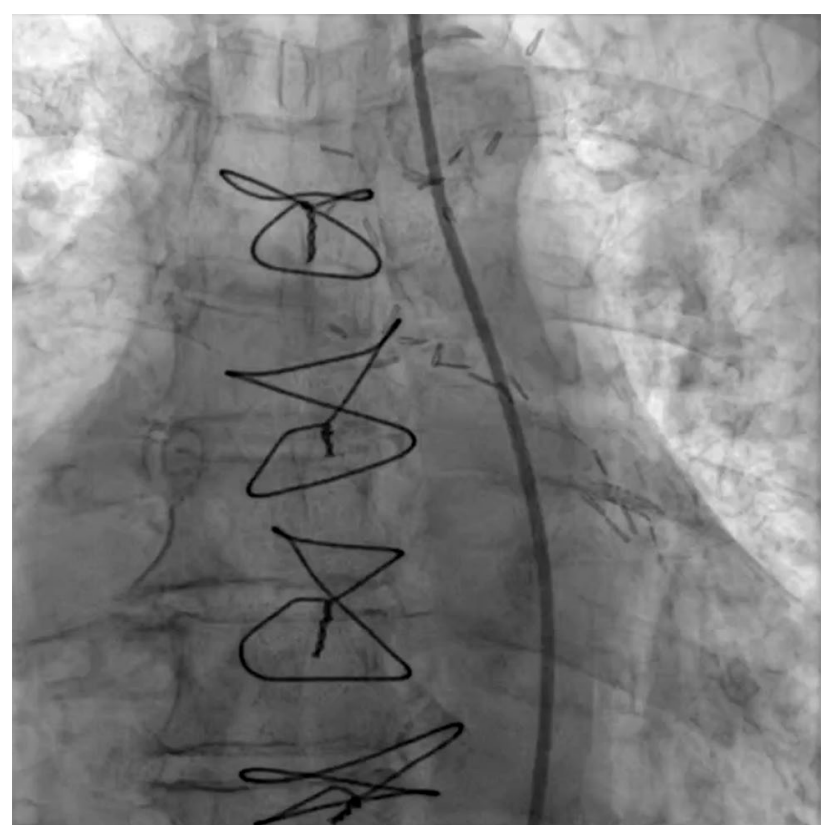

Video 2. The stenosis detected before the procedure in the proximal left subclavian artery.

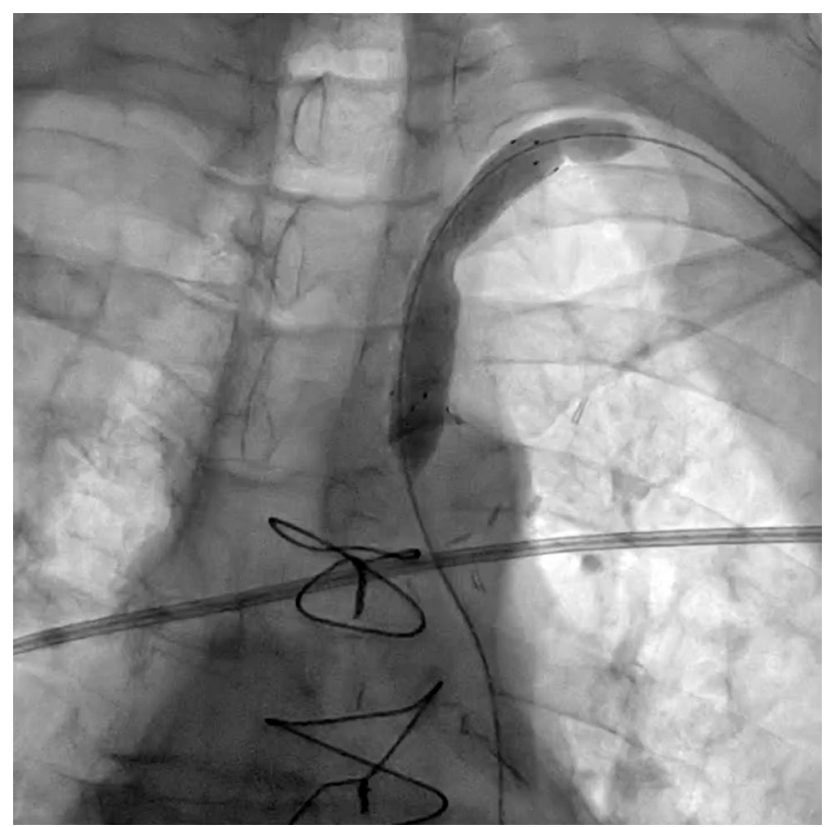

Video 3. An $8 \mathrm{~mm} \times 60 \mathrm{~mm} \times 135 \mathrm{~cm}$ drug-coated PTA balloon application after self-expandable stent on the $8 \mathrm{~mm} \times$ $40 \mathrm{~mm} \times 120 \mathrm{~cm}$ balloon.

PTA: Percutaneous transluminal angioplasty. 


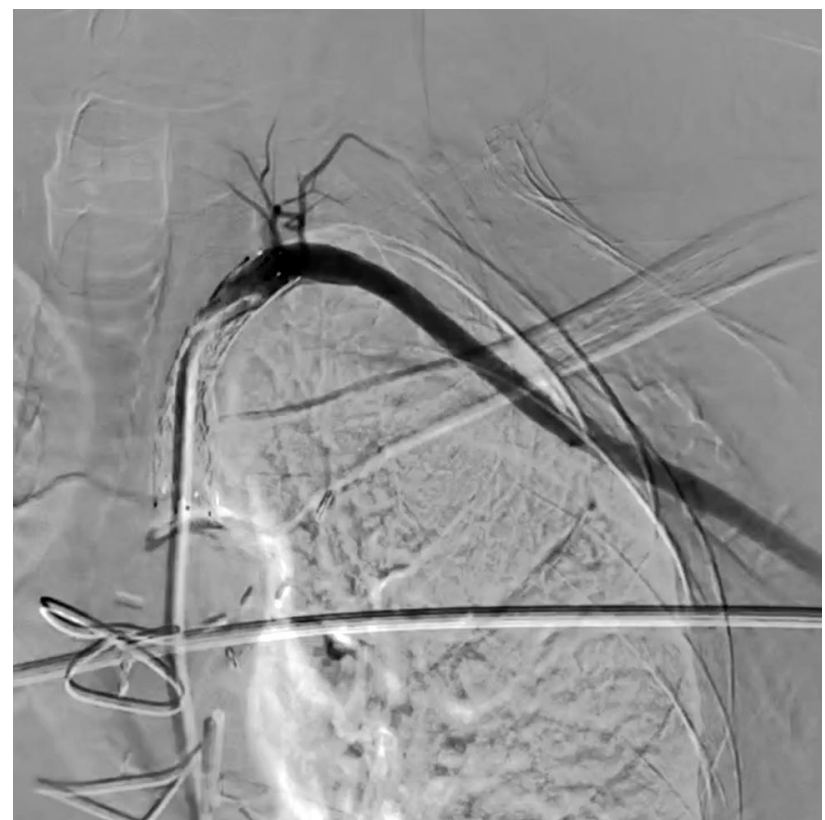

Video 4. Removal of the stenosis in the subclavian artery after the procedure and showing the filling in the LIMA.

LIMA: Left internal mammary artery.

\section{DISCUSSION}

Atherosclerosis is the major etiological factor of subclavian artery stenosis (SAS), while less common factors are embolic occlusions, infections, radiotherapy, arteritis, and external pressure (i.e., tumors and thoracic outlet syndrome). ${ }^{[4,5]}$ If there is a three-vessel or left main coronary artery disease, the SAS prevalence reaches $5.3 \% .^{[6]}$ Subclavian steal syndrome results from stenosis or complete occlusion in the pre-vertebral artery region of the subclavian artery. ${ }^{[7]}$ This phenomenon is stealing coronary flow to subclavian artery via LIMA. In patients undergoing CABG with the LIMA, long-term patency rates are higher than that of saphenous vein or radial artery. Therefore, the use of LIMA is recommended for every suitable patient. ${ }^{[8,9]}$ There should be SSS or occlusion for coronary steal syndrome with LIMA. Although it is not common in the society, it can be seen in CABG patients. ${ }^{[10]}$ Shadman et al. ${ }^{[10]}$ reported that the rate of SSS ranged from 1.9 to $7.1 \%$ in four cohorts $(\mathrm{n}=4,223)$. English et a1. ${ }^{[6]}$ also reported that there was $5.3 \% \mathrm{SSS}$ in $492 \mathrm{CABG}$ patients undergoing cardiac catheterization. If peripheral arterial disease was present, the prevalence of SSS increased up to $11.8 \%$. However, evaluating the LIMA through the left subclavian artery during coronary angiography in patients who are considered for CABG surgery is still controversial. ${ }^{[7,8]}$

Screening for SAS has been advocated by some authors, ${ }^{[7,11]}$ as CSSS has a potential to cause stable angina, ST elevation infarction, arrhythmias, or sudden death resembling to other coronary artery syndromes. ${ }^{[7,12,13]}$ Vertigo, dizziness, syncope, extremity hypo-paresthesia, and visual-auditory disturbances may be the symptoms of CSSS. ${ }^{[1,7,9,12]}$ Physical evaluation is critical to make a decision for the evaluation of the LIMA and subclavian artery. Arterial blood pressure difference between the upper extremities can simply reveal a SAS. ${ }^{[14,15]}$ However, some limitations, such as bilateral SAS, arrhythmias, or non-simultaneous measurement, can lead to a misleading SAS decision. More objective evaluation should be performed for a certain diagnosis of SAS.
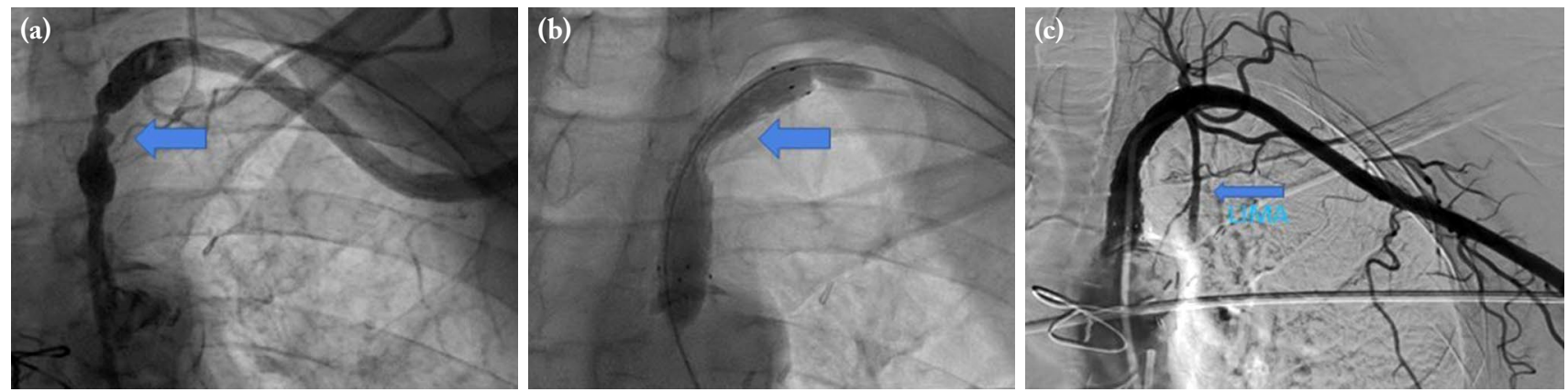

Figure 1. (a) The stenosis detected before the procedure in the proximal segment of left subclavian artery. (b) An $8 \mathrm{~mm} \times 60 \mathrm{~mm}$ $\times 135 \mathrm{~cm}$ drug-coated PTA balloon application after self-expandable stent implantation on the $8 \mathrm{~mm} \times 40 \mathrm{~mm} \times 120 \mathrm{~cm}$ balloon. (c) Removal of the stenosis in the subclavian artery after the procedure and showing the filling in the LIMA.

LIMA: Left internal mammary artery; PTA: Percutaneous transluminal angioplasty. 
In two different studies, Lapropoulos et a1. ${ }^{[5]}$ and Tamura et al. ${ }^{[16]}$ showed a very close correlation between SSS and $>20-\mathrm{mmHg}$ pressure difference between the arms. In the English et al.' $\mathrm{s}^{[6]}$ metaanalysis, a $10-\mathrm{mmHg}$ pressure difference showed a strong association with SAS $(<50 \%)$. On the other hand, Shadman et al. ${ }^{[10]}$ reported that a $15-\mathrm{mmHg}$ pressure difference was enough for SAS. However, the main limitation of blood pressure measurement is that it is an indirect measurement. In our case, there was a systolic pressure gradient of $25 \mathrm{mmHg}$ and imaging was needed to confirm the diagnosis of SSS. Arterial Doppler ultrasonography is one of the most useful, cost-effective, and sensitive diagnostic tool for the detection of SAS. ${ }^{[17,18]}$ However, conventional angiography is still the gold-standard for the diagnosis in most patients. The CTA is also used quite frequently. Physical evaluation showed SAS in our patient, and the diagnosis was confirmed by further examination. In the event that the reverse flow of LIMA is evaluated, conventional angiography should be performed for LAD.

In patients whose anginal complaints begin or continue after $\mathrm{CABG}$, coronary angiography is recommended to evaluate the subclavian artery together with the LIMA-LAD anastomosis. In patients with stenosis of the proximal subclavian artery, the LIMA-LAD flow is impaired and ischemia is detected in the region of LAD artery on myocardial perfusion scintigraphy. ${ }^{[2,11]}$ The absence of LIMA flow is seen in subclavian artery occlusion. ${ }^{[4,7,19]}$

An axillary-to-axillary or carotico-subclavian bypass are major surgery techniques for the treatment of SAS. ${ }^{[7,14]}$ Percutaneous transluminal angioplasty and subclavian artery bypass surgery associated with stenting are the most commonly used methods in the treatment of SSS. The PTA is preferred owing to its low morbidity and shorter hospital stay. ${ }^{[4,20,21]}$ Also, in the 2017 European Society of Cardiology (ESC) guidelines, both revascularization options (stenting or surgery) should be considered and discussed case by case according to the lesion characteristics and patient's risk. ${ }^{[22]}$ In a study, the stroke rate was $2.6 \%$ and $2.4 \%$ who were treated by PTA and open surgery, respectively. ${ }^{[23]}$ In such cases, endovascular treatment is mostly the preferred strategy. ${ }^{[21-23]}$ In a retrospective study conducted by De Vries et al., ${ }^{[24]}$ the success of PTA and stenting was 93\%, and the patency rate was $93 \%$ after three years. Although the carotico-subclavian artery bypass surgery method is relatively less frequently performed, the success rate was reported as $98 \%$, with a 10 -year patency rate of around $95 \% .{ }^{[19]}$ In the study by Jahic et al., ${ }^{[25]}$ PTA treatment was performed in 22 of 26 patients, and a $100 \%$ patency rate was achieved within one-year follow-up. As a result of this study, PTA treatment was suggested for those with subclavian stenosis, while surgical treatment was recommended for those with obstruction. ${ }^{[25]}$

In recent years, new laser cutting balloon therapies and drug-coated balloon therapies have been developed. ${ }^{[9,26]}$ Self-expendable stents have more stronger radial force and easier to deploy in more calcific lesions. ${ }^{[9,25]}$ Medical therapy after PTA or surgery is similar. Antiaggregant-based therapy (acetylsalicylic acid and clopidogrel) is the mainstay, although patient-based individualized therapy is always the primary preference. Anticoagulant therapy can be prescribed in cases who has a concomitant atrial fibrillation or a hypercoagulation state. ${ }^{[9,19,27]}$ In this case, we preferred PTA treatment, due to the advanced age of the patient and the presence of a stenosis rather than a complete occlusion of the subclavian artery. Additionally, the lesion was deemed suitable for a percutaneous intervention.

The literature consists controversial issues. First and more controversial of them is the performance of a subclavian artery and LIMA imaging during preoperative angiography. The second issue is using the LIMA in patients receiving a surgical or endovascular intervention for SAS. ${ }^{[4,24]}$ However, in a study, CABG with LIMA was performed at the same day of successfully treated SAS patients and the authors used acetylsalicylic acid after CABG. ${ }^{[28]}$ The third is the treatment selection: surgery versus PTA. The literature review reveals that patient-based selection is more important and both surgery and PTA treatment are safe..$^{[4,7,22]}$

In conclusion, although coronary SSS is rare, it is a critical syndrome due to its possible role in the disruption of myocardial perfusion and development of angina pectoris and symptoms of dyspnea. Percutaneous treatment is safe and effective in eligible cases. We recommend physical examination of SAS for $\mathrm{CABG}$ candidates preoperatively and angiographic evaluation of the subclavian artery in patients who has a concomitant peripheral arterial disease.

\section{Declaration of conflicting interests}

The authors declared no conflicts of interest with respect to the authorship and/or publication of this article. 


\section{Funding}

The authors received no financial support for the research and/or authorship of this article.

\section{REFERENCES}

1. Aithal JK, Ulrich M. Images in clinical medicine. Subclavian steal syndrome. N Engl J Med 2010;363:e15.

2. Boztosun B, Avcı A, Saglam M, Meriç M. Coronary subclavian steal syndrome: a case report. Turk Gogus Kalp Dama 2010;18:141-4.

3. Chan-Tack KM. Subclavian steal syndrome: a rare but important cause of syncope. South Med J 2001;94:445-7.

4. Che W, Dong H, Jiang X, Peng M, Zou Y, Song L, et al. Subclavian artery stenting for coronary-subclavian steal syndrome. Catheter Cardiovasc Interv 2017;89:601-8.

5. Labropoulos N, Nandivada P, Bekelis K. Prevalence and impact of the subclavian steal syndrome. Ann Surg 2010;252:166-70.

6. English JA, Carell ES, Guidera SA, Tripp HF. Angiographic prevalence and clinical predictors of left subclavian stenosis in patients undergoing diagnostic cardiac catheterization. Catheter Cardiovasc Interv 2001;54:8-11.

7. Cua B, Mamdani N, Halpin D, Jhamnani S, Jayasuriya S, Mena-Hurtado C. Review of coronary subclavian steal syndrome. J Cardiol 2017;70:432-7.

8. Karthik S, Fabri BM. Left internal mammary artery usage in coronary artery bypass grafting: a measure of quality control. Ann R Coll Surg Engl 2006;88:367-9.

9. Kilic ID, Alihanoglu YI, Yildiz BS, Taskoylu O, Evrengul H. Coronary subclavian steal syndrome: a case-based review. Herz 2015;40:250-4.

10. Shadman R, Criqui MH, Bundens WP, Fronek A, Denenberg JO, Gamst AC, et al. Subclavian artery stenosis: prevalence, risk factors, and association with cardiovascular diseases. J Am Coll Cardiol 2004;44:618-23.

11. Murai S, Itami H, Nishi K, Otsuka S, Kusaka N, Nishiura $\mathrm{T}$, et al. Coronary subclavian steal syndrome successfully treated with subclavian artery stenting: A report of 2 cases. J Stroke Cerebrovasc Dis 2017;26:e64-e68.

12. Kursaklioglu H, Kose S, Iyisoy A, Amasyali B, Celik T, Aytemir K, et al. Coronary-subclavian steal syndrome presenting with ventricular tachycardia. Yonsei Med J 2009;50:852-5.

13. Wu CH, Sung SH, Chang JC, Huang CH, Lu TM. Subclavian artery thrombosis associated with acute ST-segment elevation myocardial infarction. Ann Thorac Surg 2009;88:2036-8.

14. Gayá J, Del Río Prego A, Guilleuma J, Vela P, Arribas A, López Parra JJ, et al. Coronary steal syndrome. Cardiovasc Surg 1993;1:186-9.

15. Kleefstra N, Houweling ST, Bilo HJ. Interarm blood pressure difference and vascular disease. Lancet 2012;380:23.

16. Tamura K, Kihara K, Chikazawa G, Sakaguchi T, Yoshitaka $\mathrm{H}$. A case of dissection and rupture of the innominate artery in acute type a aortic dissection. Ann Vasc Dis 2016;9:117-9.

17. Clark CE, Taylor RS, Shore AC, Ukoumunne OC, Campbell JL. Association of a difference in systolic blood pressure between arms with vascular disease and mortality: a systematic review and meta-analysis. Lancet 2012;379:905-14.

18. Vecera J, Vojtísek P, Varvarovský I, Lojík M, Másová K, Kvasnicka J. Non-invasive diagnosis of coronary-subclavian steal: role of the Doppler ultrasound. Eur J Echocardiogr 2010;11:E34.

19. Qi L, Gu Y, Zhang J, Yu H, Li X, Guo L, et al. Surgical treatment of subclavian artery occlusion. Zhongguo Xiu Fu Chong Jian Wai Ke Za Zhi 2010;24:1030-2.

20. Ergenç H, Gündüz Y, Vatan M, Tamer A . Subklaviyan Çalma Sendromu: Bir Olgu Sunumu. Sakarya Tıp Dergisi 2014;4:160-3.

21. Kara İ, Köksal C, Boyacıŏlu K, Uslu Z, Büyükbayrak F, Çakalağaoğlu $\mathrm{C}$, et al. The early and midterm results of carotid-subclavian and subclavian-subclavian bypass in the treatment of subclavian steal syndrome. Turk Gogus Kalp Dama 2012;20:761-7.

22. Aboyans V, Ricco JB, Bartelink MEL, Björck M, Brodmann M, Cohnert T, et al. 2017 ESC Guidelines on the Diagnosis and Treatment of Peripheral Arterial Diseases, in collaboration with the European Society for Vascular Surgery (ESVS): Document covering atherosclerotic disease of extracranial carotid and vertebral, mesenteric, renal, upper and lower extremity arteriesEndorsed by: the European Stroke Organization (ESO)The Task Force for the Diagnosis and Treatment of Peripheral Arterial Diseases of the European Society of Cardiology (ESC) and of the European Society for Vascular Surgery (ESVS). Eur Heart J 2018;39:763-816.

23. Klitfod L, Jensen LP. Treatment of chronic upper limb ischaemia is safe and results are good. Dan Med J 2014;61:A4859.

24. De Vries JP, Jager LC, Van den Berg JC, Overtoom TT, Ackerstaff RG, Van de Pavoordt ED, et al. Durability of percutaneous transluminal angioplasty for obstructive lesions of proximal subclavian artery: long-term results. J Vasc Surg 2005;41:19-23.

25. Jahic E, Avdagic H, Iveljic I, Krdzalic A. Percutaneous transluminal angioplasty of subclavian artery lesions. Med Arch 2019;73:28-31.

26. Eggebrecht H, Naber CK, Oldenburg O, Herrmann J, Haude $\mathrm{M}$, Erbel R, et al. Percutaneous transluminal laser guide wire recanalization of chronic subclavian artery occlusion in symptomatic coronary-subclavian steal syndrome. Catheter Cardiovasc Interv 2000;51:500-4.

27. Linni K, Ugurluoglu A, Mader N, Hitzl W, Magometschnigg $\mathrm{H}$, Hölzenbein TJ. Endovascular management versus surgery for proximal subclavian artery lesions. Ann Vasc Surg 2008;22:769-75.

28. Hwang HY, Kim JH, Lee W, Park JH, Kim KB. Left subclavian artery stenosis in coronary artery bypass: prevalence and revascularization strategies. Ann Thorac Surg 2010;89:1146-50. 